\title{
Access to livelihood assets among youth with and without disabilities in South Africa: Implications for health professional education
}

\author{
Theresa Lorenzo, Jane Murray Cramm
}

Purpose. This study compared access to 5 livelihood assets among disabled and non-disabled youth, to inform health professionals on inequities related to disability and to monitor the transformation agenda aimed at creating an inclusive society.

Methods. Fieldworkers interviewed 989 youth (18 - 35 years; 523 (52.9\%) disabled youth (DY), 466 (47.1\%) non-disabled youth (NDY)) at 9 sites in 5 South African provinces. Descriptive statistics were used to describe demographic characteristics and livelihood assets. Chi-squared and $t$-tests were used for comparisons.

Results. Doctors at hospitals and nurses at clinics are health professionals most frequently seen. Far fewer DY than NDY attended and completed school. Unemployment was markedly more common among DY than among NDY. Barriers to accessing employment for DY were poor health and lack of skills development, and a lack of job opportunities for NDY. Both groups received the same amount of support from immediate household members, but significantly more NDY received support from extended family, friends, partners, and neighbours. They spent significantly more time engaging in all free-time activities. NDY reported more access to bathrooms, phone, and newspapers, as well as public services and the business sector. Participation and access were limited for both groups because of inaccessible public transport.

Conclusion. This paper shows that DY have a greater struggle to access livelihood assets than non-disabled peers. The Disability Studies Academic Programme at the University of Cape Town is an initiative that seeks to take specific focused action with disability organisations in order to address the inequities faced by disabled youth to ensure their inclusion in development to the same degree as their non-disabled peers.

S Afr Med J 2012;102(6):578-581.
Since its inception in the early 1980s, the disability rights movement has called for inclusion and equality in all aspects of economic, political, cultural, and social life. However, few resources were made available, resulting in very little practical impact. ${ }^{1}$ Miller and Albert $^{2}$ adapted a definition of gender mainstreaming from UN Development Programmes for disability:

Mainstreaming disability into development cooperation is the process of assessing the implications for disabled people of any planned action, including legislation, policies and programmes, in all areas and at all levels. It is a strategy for making disabled people's concerns and experiences an integral dimension of the design, implementation, monitoring and evaluation of policies and programmes in all political, economic and societal spheres so that disabled people benefit equally and inequality is not perpetuated. The ultimate goal is to achieve disability equality.

The United Nations Convention on the Rights of Persons with Disabilities (CRPD) ${ }^{3}$ and the new World Health Organization (WHO) Community Based Rehabilitation (CBR) guidelines ${ }^{4}$ provide blueprints for disability-inclusive development. In post-apartheid South Africa, poverty and lack of economic empowerment persist among disadvantaged groups and especially for disabled people. ${ }^{5}$

Disability Studies and Occupational Therapy, Department of Health and Rehabilitation Sciences, Faculty of Health Sciences, University of Cape Town Theresa Lorenzo, BSc (OT), HDipEdAd, MSc, PhD

Institute of Health Policy and Management (iBMG), Erasmus University, Rotterdam, The Netherlands

Jane Murray Cramm, $\mathrm{PhD}$
The sociopolitical underpinnings of healthcare, education, and employment provide a somewhat bleak outlook for many families, particularly those with a disabled member. ${ }^{6}$ The democratically elected government has placed great emphasis on human rights. In comparison with other middle- and low-income countries, a relatively high level of social support (e.g. disability grants) has been made available. ${ }^{7}$ Yet many barriers to full participation in society remain for disabled people. ${ }^{8-12}$ 'Livelihood' refers to the assets that people use to earn enough money to support themselves and their families through a variety of economic activities. ${ }^{13}$ There are 5 categories: human assets (health and education), social assets (social support systems and use of free time), financial assets (work and other sources of income), physical assets (living situation, facilities and services) and natural assets (resource-based activities, e.g. gathering firewood and vegetation). ${ }^{13}$

DY are identified as a priority target group requiring particular support and assistance, ${ }^{14,15}$ but there is currently a lack of reliable information about the ability of DY to participate fully in society. Identification and comparison of access to livelihood assets among DY and NDY is the first step to resolving these inequities. Knowledge of the factors impeding, or facilitating, DY's efforts to sustain their livelihood would inform disability studies in the curricula of health professionals, drive research by higher education institutions (HEIs) and influence action by government.

\section{Methods}

This cross-sectional study made a comparison of access to 5 livelihood assets by participating DY and NDY living in underserviced communities in SA as part of a larger study, the Disabled Youth Enabling Sustainable Livelihoods (DYESL) project. This project was initiated in 2007 by the Occupational Therapy and Disability Studies Divisions at UCT, with the participation of occupational therapy departments from 5 other universities in SA: KwaZulu-Natal (UKZN), Witwatersrand (Wits), Limpopo-MEDUNSA campus, 
Pretoria (UP), and the Free State. The questionnaire received ethical approval from UCT, Wits, UP and UKZN. Each participant was asked to complete an informed consent form prior to commencement of the interview.

Youth were recruited in 9 communities in 5 provinces (Gauteng, North West, KwaZulu-Natal, Western Cape and Free State) where the occupational therapy departments have long-established relationships. While the UN defines youth as those aged $15-24$ years, in South Africa youth are defined as persons aged 14 - 35 years, based on the mandates of the National Youth Commission Act (1996) and the National Youth Policy (2000). This study included individuals aged 18 - 35 years, 18 being the age when youth typically leave school and enter the labour market (and the age of consent). Physical, sensory, and/or intellectual/mental impairment were criteria for selecting DY.

Fieldworkers used a snowballing strategy to identify DY in each study site. They then recruited an age-matched ( \pm 5 years) NDY who lived next door to or across the road from each participating DY. A sample of 200 youth (100 DY, $100 \mathrm{NDY}$ ) was selected in each province. In 2009 fieldworkers interviewed 989 individuals (523 (52.9\%) DY, 466 (47.1\%) NDY).

Fieldworkers conducted face-to-face interviews using a questionnaire to identify access to the 5 categories of livelihood assets ${ }^{13}$ mentioned above. The questionnaire was developed from qualitative data from phase 1 of the DYESL study concerning DY's livelihood strategies. It sought demographic information and posed a combination of single-option and multiple-response questions related to individual and household items linked to the livelihood assets. A 2-day training workshop was held in each province, following which the questionnaire was piloted by all fieldworkers; changes to the questionnaire were then finalised in a research team workshop.

Fieldworkers carried out individual 30 - 45-minute interviews with respondents in their home language. Data collection took place during the day and was limited to the working week, thus excluding any individuals employed in some part- or full-time capacity.

Descriptive statistics were used to outline demographic characteristics and the 5 livelihood assets. Chi-squared and $t$-tests were used to perform comparisons where appropriate. The data set was analysed using PASW/SPSS software (version 18).

\section{Results}

Table 1 summarises the demographic characteristics of DY and NDY. Age, gender and cohabitation with partners differed between the 2 groups. A significantly larger proportion of DY was female $(62.0 \%$ v. $46.9 \% ; p \leq 0.001)$ and DY were, on average, significantly older than NDY ( 26.1 v. 25.7 years; $p \leq 0.05$ ). All youth self-reported and DY self-categorised themselves. Of the latter, the largest proportion was affected by a physical disability ( $n=231,44.2 \%)$, followed by an intellectual disability $(n=169,32.3 \%)$.

A similar proportion of youth in each group (about 50\%) lived with their parents. A significantly higher proportion of NDY lived with their partners $(22.5 \%$ v. $11.5 \%$; $p \leq 0.001)$.

\section{Human livelihood asset: health facilities and education} DY reported seeing both doctors at hospitals ( $n=397,82.5 \%$ of cases) and nurses ( $n=402,83.7 \%$ of cases) most frequently; NDY see nurses at clinics more frequently $(n=355,89.9 \%)$. There seemed to be less awareness of community rehabilitation workers, home-based carers and rehabilitation therapists than of social workers.

We dichotomised access to schooling into (1) respondents who had attended and/or completed school and (0) respondents who had never attended school. There was a large difference in school attendance and/or completion between NDY and DY (99.3\% v. $82.4 \% ; p \leq 0.001)$. Both groups indicated financial reasons as the chief barriers to completing school.

\section{Social livelihood assets: support systems and free time}

Respondents were asked to indicate individuals who provided them with help or support from a predetermined list. Responses showed no difference between groups with regard to support received from people in their immediate household. A significantly higher proportion of NDY than DY received support from their extended family, friends and partners (Table 2). Lack of knowledge of social services and non-governmental organisations (NGOs) was a barrier for both groups, while accessibility was a further barrier for DY.

Responses to questions about engagement in free-time activities showed a significant difference between DY and NDY. NDY spent more time visiting friends, engaging in sports, going to the library, watching movies at home, going to the cinema, going to shopping malls and going to nightclubs/shebeens/taverns (Table 3).

Financial livelihood assets: work and sources of income There was a large difference in employment between DY and NDY (32.9\% v. $13.1 \% ; p \leq 0.001)$. The major barrier to employment for DY was poor health $(n=162,47.9 \%)$, followed by lack of jobs in the area ( $n=123,36.4 \%)$. Among NDY, the largest proportion indicated lack of jobs in the area $(n=142,62.3 \%)$ followed by lack of skills $(n=75$, $32.9 \%)$ and (lack of) education/further training ( $n=56,24.6 \%)$. A

Table 1. Demographic characteristics of all respondents

\begin{tabular}{|c|c|c|c|c|c|c|}
\hline Characteristic & $\begin{array}{l}\text { Total }(N=989) \\
(\%)\end{array}$ & $\begin{array}{l}\text { Non-disabled }(n=466) \\
(\%)\end{array}$ & $\begin{array}{l}\text { Disabled }(n=523) \\
(\%)\end{array}$ & $x^{2}$ & $t$ & $p$-value \\
\hline Female & 54.0 & 62.0 & 46.9 & 22.5 & & $\leq 0.001$ \\
\hline Age, mean years $( \pm S D)$ & $26.1( \pm 5.0)$ & $25.7( \pm 4.6)$ & $26.5( \pm 5.3)$ & & 2.481 & 0.013 \\
\hline $18-25$ & 47.2 & 50.1 & 44.6 & & & \\
\hline $25-35$ & 52.8 & 49.9 & 55.4 & & & \\
\hline \multicolumn{7}{|l|}{ Living situation } \\
\hline Living with parents & 50.2 & 47.0 & 53.0 & 3.5 & & 0.065 \\
\hline Living with partner & 16.7 & 22.5 & 11.5 & 21.7 & & $\leq 0.001$ \\
\hline Living with family & 19.1 & 17.4 & 20.7 & 1.7 & & 0.196 \\
\hline Living alone & 3.1 & 3.0 & 3.3 & 0.1 & & 0.857 \\
\hline
\end{tabular}


Table 2. Social support systems

\begin{tabular}{|c|c|c|c|c|c|}
\hline Type of support system & $\begin{array}{l}\text { Total }(N=989) \\
(\%)\end{array}$ & $\begin{array}{l}\text { Non-disabled }(n=466) \\
(\%)\end{array}$ & $\begin{array}{l}\text { Disabled }(n=523) \\
(\%)\end{array}$ & $\chi^{2}$ & $p$-value ${ }^{*}$ \\
\hline Immediate household & 92.9 & 92.2 & 93.5 & 0.5 & 0.519 \\
\hline Extended family & 74.5 & 78.1 & 71.5 & 4.9 & 0.029 \\
\hline Friends & 66.9 & 70.4 & 63.9 & 4.1 & 0.044 \\
\hline Partner (boyfriend/girlfriend) & 53.5 & 71.3 & 37.4 & 94.7 & $\leq 0.001$ \\
\hline Neighbours & 60.7 & 56.3 & 64.2 & 5.5 & 0.020 \\
\hline
\end{tabular}

Table 3. Free-time activities

\begin{tabular}{|c|c|c|c|c|c|}
\hline Type of activity & $\begin{array}{l}\text { Total }(N=989) \\
(\%)\end{array}$ & $\begin{array}{l}\text { Non-disabled }(n=466) \\
(\%)\end{array}$ & $\begin{array}{l}\text { Disabled }(n=523) \\
(\%)\end{array}$ & $x^{2}$ & $p$-value ${ }^{*}$ \\
\hline Visiting friends & 80.3 & 88.4 & 73.2 & 35.1 & $\leq 0.001$ \\
\hline Sports & 47.4 & 57.8 & 38.0 & 37.1 & $\leq 0.001$ \\
\hline Library & 35.7 & 45.6 & 26.8 & 35.5 & $\leq 0.001$ \\
\hline Watching movies at home & 86.3 & 92.4 & 80.9 & 26.2 & $\leq 0.001$ \\
\hline Cinema & 26.8 & 34.6 & 19.9 & 25.0 & $\leq 0.001$ \\
\hline Shopping mall & 76.3 & 85.6 & 68.0 & 40.8 & $\leq 0.001$ \\
\hline Nightclubs/shebeens/taverns & 24.7 & 34.5 & 16.1 & 41.5 & $\leq 0.001$ \\
\hline
\end{tabular}

Table 4. Access to or availability of facilities

\begin{tabular}{|c|c|c|c|c|c|}
\hline Type of facility & $\begin{array}{l}\text { Total }(N=989) \\
(\%)\end{array}$ & $\begin{array}{l}\text { Non-disabled }(n=466) \\
(\%)\end{array}$ & $\begin{array}{l}\text { Disabled }(n=523) \\
(\%)\end{array}$ & $\chi^{2}$ & $p$-value \\
\hline Water & 92.0 & 92.3 & 91.8 & 0.1 & 0.815 \\
\hline Bathroom & 27.2 & 30.5 & 24.3 & 4.8 & 0.032 \\
\hline Toilet & 93.8 & 93.1 & 94.5 & 0.7 & 0.428 \\
\hline Electricity & 89.7 & 91.0 & 88.5 & 1.6 & 0.211 \\
\hline Phone & 86.9 & 90.6 & 83.6 & 10.6 & $\leq 0.001$ \\
\hline Television & 87.3 & 89.3 & 85.5 & 3.2 & 0.085 \\
\hline Radio & 84.7 & 86.9 & 82.8 & 3.2 & 0.077 \\
\hline Newspaper & 64.1 & 71.7 & 57.4 & 21.9 & $\leq 0.001$ \\
\hline
\end{tabular}

larger proportion of DY (89.4\%) indicated that social security grants were the main source of income, whereas $65.1 \%$ of NDY received salaries or wages.

\section{Physical livelihood assets: living conditions and access to facilities and services}

The majority of both DY (67.4\%) and NDY (71.2\%) indicated that their primary dwelling was some form of brick home. Similar proportions of DY and NDY indicated shacks (DY 22.2\%, NDY 20.3\%), shelters (DY 4.5\%, NDY 3.3\%), and mud houses (DY 5.7\%, NDY 5.0\%) as their primary dwellings.

There was no difference between DY and NDY households regarding the availability of a toilet in the house or access to water facilities, electricity, television, and radio. However, NDY had significantly more access compared with DY to a bathroom, phone and newspapers (Table 4).
Access to all other services differed significantly between the 2 groups. In contrast to DY, NDY had significantly greater access to police, municipal services, labour, banks, internet cafés and post offices (Table 5). Attitudes of taxi drivers and their passengers were barriers to accessible public transport for DY.

\section{Natural livelihood assets: resource-based activities}

Similar proportions of DY (41.2\%) and NDY (48.5\%) reported gathering firewood or vegetation. Smaller proportions of DY (22.9\%) and NDY (20.1\%) reported farming while half of DY and NDY reported access to land/fields as a resource.

\section{Discussion}

A long path remains to be travelled before the goal of disability equity in development is achieved. These results show that the livelihoods of NDY are more secure than those of DY in terms of education, 
Table 5. Access to services

\begin{tabular}{|c|c|c|c|c|c|}
\hline Type of service & $\begin{array}{l}\text { Total }(N=989) \\
(\%)\end{array}$ & $\begin{array}{l}\text { Non-disabled }(n=466) \\
(\%)\end{array}$ & $\begin{array}{l}\text { Disabled }(n=523) \\
(\%)\end{array}$ & $\chi^{2}$ & $p$-value ${ }^{*}$ \\
\hline Police & 78.6 & 84.7 & 73.2 & 18.2 & $\leq 0.001$ \\
\hline Municipal services & 66.9 & 69.8 & 64.4 & 2.8 & 0.054 \\
\hline Labour & 29.2 & 38.4 & 20.9 & 31.3 & $\leq 0.001$ \\
\hline Bank & 72.0 & 84.2 & 61.2 & 56.9 & $\leq 0.001$ \\
\hline Internet café & 29.5 & 38.7 & 21.3 & 30.1 & $\leq 0.001$ \\
\hline Post office & 58.4 & 68.6 & 49.1 & 32.8 & $\leq 0.001$ \\
\hline
\end{tabular}

support in intimate relationships and engagement in free-time activities, work, and quality of facilities and access to services.

Higher education institutions such as UCT play a role in capacitating future health practitioners and policy makers with the knowledge and skills to reduce the inequities faced by DY. Doctors and nurses should be encouraged to increase awareness of, and referral to, rehabilitation services so that DY gain access to resources that would promote their development. Likewise, occupational therapists and social workers could play a critical role in the retention of DY in schooling, which might facilitate access to higher education on the part of DY, so that opportunities for employment are enhanced.

Increased accessibility to public services and public transport is required. The Disability Studies Academic Programme at UCT encourages lecturers and students in under- and postgraduate programmes to engage in socially responsive projects to promote both in-service learning and collaborative research (with practitioners in public service and NGOs including disabled people's organisations ${ }^{15}$ ). This initiative contributes to disability-inclusive development at all levels of government.

This study has limitations: data were collected only on weekdays during daylight hours, which may have excluded youth with fulltime employment and those attending educational institutions; the cross-sectional design hampered the ability to draw causal inferences.

\section{Conclusion}

That DY struggle to access the livelihood assets of education, employment, social support systems, free-time activities, facilities, and services, when compared with their non-disabled counterparts, is confirmed by this survey. To address these inequities, the Disability Studies Academic Programme at UCT (informed by the CRPD and CBR guidelines), in collaboration with disability organisations, seeks to encourage changes in the curricula that will guide the training of health professionals. Monitoring these educational changes and their impact on the future capacity of service providers to address the inequities that prevent full participation of DY in society and constitute a violation of their rights will provide fruitful avenues of research.

Acknowledgements. This research project was funded by the South Africa Netherlands Research Programme on Alternatives in Development (SANPAD), the National Research Foundation of South Africa, and the University Research Committee of UCT. The views expressed in the paper are those of the authors. Gratitude is extended to all members of the research team as well as to the youth who responded to the survey.

\section{References}

1. Albert B. Lessons from the Disability Knowledge and Research Programme. Overseas Development Group and DFID: University of East Anglia, 2006.

2. Miller C, Albert B. Mainstreaming disability in development: Lessons from gender mainstreaming March 2005. http://www.dfid.gov.uk/r4d/PDF/outputs/Disability/RedPov_gender.pdf (accessed 25 January 2012).

3. UN Convention on the Rights of Persons with Disabilities 2006. New York: UN, 2006

4. World Health Organization. Community Based Rehabilitation Guidelines 2010. Geneva: WHO, 2010. 5. Office of the Deputy President. Integrated National Disability Strategy, White Paper of the Office of the Deputy President of South Africa, November. Cape Town: Rustica Press, 1997.

. Levin K. Paediatric traumatic brain injury in South Africa: some thoughts and considerations. Disabil Rehabil 2004;26:306-314.

. Nattrass N. Disability and welfare in South Africa's era of unemployment and AIDS. Cape Town: Centre for Social Science Research, University of Cape Town, 2006.

8. Booth A Ainscow M. Index for Inclusion: Developing Learning and Participation in Schools. Bristol, UK: Centre for Studies on Inclusive Education, 2002. De Klerk HM, Ampousah L. The physically UK: Centre for Studies on Inclusive Education, 2002. De Klerk HM,
disabled woman's experience of self. Disabil Rehabil 2003;25:1132-1139.

disabled woman's experience of self. Disabil Rehabil 2003;25:1132-1139.
9. Gcaza S, Lorenzo T. Discovering the barriers that stop children from being children: The right to the provision of mobility devices. SAJOT 2008;39(1):16-21.

0. Cramm JM, Nieboer AP, Finkenflügel H, Lorenzo T. Disabled youth in South Africa: Barriers to education. Int J Disabil Hum Dev 2012 (in press).

1. Cramm JM, Nieboer AP, Finkenflügel H, Lorenzo T. Comparison of barriers to employment among youth with and without disabilities in South Africa. WORK 2012 (in press).

2. Butler M. The sustainable livelihoods approach: core concepts and framework. Paper prepared for the Disability Action Research Team (DART), 2002.

13. Lorenzo T. 'We are also travellers': An action story about disabled women mobilising for an accessible public transport system in Khayelitsha and Nyanga, Cape Metropole, South Africa. SAJOT 2008; $39(1): 32-40$.

14. McKenzie J. Disability activism and participation. In Lorenzo T, ed. Disability Catalyst Africa: Intentions, pillars and players. Series No. 1. Cape Town: Disability Innovation Africa, UCT, 2011:13-21.

Accepted 6 February 2012. 